\title{
Comparison of Kinematic and Kinetic Variables of Sprinters Running Barefoot and with Shoe Spikes
}

\author{
Kuldeep Singh and Mahipal
}

\begin{abstract}
Aim: To study the difference between barefoot running and running with spikes conditions of sprinters in order to provide information about the potential effects of footwear on competitive runners. Method: The twenty six $(n=26)$ male sprinters of state/ inter-collegiate level participated and their age range 17 to 25 years were purposively selected as subjects from Haryana State, India. The $100 \mathrm{~m} \& 200 \mathrm{~m}$. sprint test, acceleration ability by $30 \mathrm{~m}$ run, stride frequency by high knee action for one minutes, explosive leg strength by standing broad jump and force by using formula $(\mathrm{f}=\mathrm{ma})$ were measured in both bare foot and running with spikes running conditions of sprinters. Results: A statistical significant difference was observed for $100 \mathrm{~m} \& 200 \mathrm{~m}$. sprint test, acceleration ability, stride frequency, explosive leg strength and force in both bare foot and running with spikes running conditions of sprinters. The mean values of $100 \mathrm{~m}$ sprint, $200 \mathrm{~m}$ sprint, and acceleration run ability of sprinters run with shoe spikes conditions were found less as compared to sprinters run with barefoot. Hence it clearly indicates that shoe spike sprinters perform better as compared to barefoot running sprinters. Conclusion: It was concluded that shoe spike sprinters perform better for sprint of $100 \mathrm{~m}, 200 \mathrm{~m}, 30 \mathrm{~m}$, standing broad jump and force as compared to barefoot running sprinters.
\end{abstract}

Kuldeep Singh, Assistant Professor, Department of Physical Education, Indira Gandhi National College, Ladwa- Kurukshetra (Haryana) India

E-mail:kuldeepskkr@gmail.com

Mahipal, Athletic Coach, Department of Sports and Youth Affairs,Panipat (Haryana) India

E-mail:mahi.gaur13@gmail.com
Key Words: Acceleration, Explosive Strength, Force, Stride Frequency, Standing Broad Jump

DOI: $10.18376 / j e s p / 2017 / v 13 / i 1 / 111272$

\section{Introduction}

Running has also been mentioned in the myth and legends of ancient civilizations, such as Greece and Egypt. Professional messengers ran between cities carrying news of importance. In the year of 490 BC the Persians attacked the Greek city of Marathon. The courier Pheippides ran from Marathon to Sparta $(240 \mathrm{~km})$ in call for aid. When the battle was won Pheippides ran to Athens (40 $\mathrm{km}$ ) with the news of victory, but he died delivering the massage according to ancient Greek storyteller Herodotus (Christensen et. al., 2009). In the 1960 Olympic Games, an Ethopian barefoot runner named Abebe Bikila won the Marathon gold with a time 2:15:16. This set the marathon world record, and is considered a respectable time to this day. This was probably one of the first accounts in modern times of someone winning a major competition while running completely without shoes (Christopher McDougall, 2009). Zola Budd is another barefoot runner that won recognition by setting a world record at $5000 \mathrm{~m}$ in 1985, finishing at 15:01:83 (Christopher McDougall, 2009). This is question that many have sought to answer. One recent trend is the interest in barefoot running. There are many voices on the Internet that believe it may be more beneficial to run barefoot than the standard practice of running in cushioned shoes (Barefoot runner, 2012). Manufactures of bare foot sports shoes currently state that wearing their shoes will stimulate 


\section{Journal of Exercise Science \& Physiotherapy, Vol. 13, No. 1, 2017

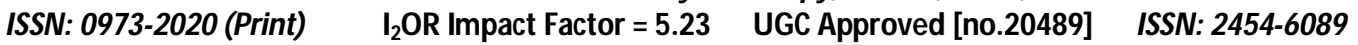 \\ (Online)}

and strengthen muscles in the feet and lower legs, improving general foot health and reducing the risk of injury. Further stimulate neural function important to balance and agility. The shoes would even help you to unleash your optimal running stride. The impact force has been a major concern for shoe designers and manufacturers, as one of the primary roles for running shoes is to provide shock absorption (Cavanagh 1980; Nigg \& Wakeling 2001). In reviewing the research, from the Nike Sport Research Laboratory published an article in which he postulated that the three main needs of the athlete are performance, injury protection, and comfort (Lafortune,2008). Additionally, for improving the athlete performance the total weight of the shoe has been reduced. Hence, racing tracks, shoes and spikes have been developed to help facilitate optimal performance (Cavanagh \& Lafortune 1980; Denton 2005). William (2001) stated "Natural walking is mechanically impossible for any shoe-wearing person. Natural walking and footwear are mechanically incompatible because shoes convert the natural foot into the unnatural which doctors consider normal." In comparison to most running shoes, spikes and racing track surface have less cushioning and a flat, thinner heel to produce a lighter shoe for tournaments and practice/training sessions. While competitive footwear has its time and place, it is assumed that this type of shoe should be used with alertness and awareness of the possible increased injury risks (Denton, 2005). The body need to adapt to barefoot running anatomically if one previously has been running only in shoes and the lack of proprioception in a minimal shoe affect running form (Lieberman,2012). Additional research suggests that cushioning in running shoes can cause excessive subtalar joint motion (Clement, et al., 1981). The change in shock absorption properties of running shoes was evaluated and found shoes tested by the volunteer runners showed a marked reduction in shock absorption with mileage. The loss, was not as great as in the machine-simulated running, with approximately $70 \%$ of initial shock absorption retained at 500 miles (Cook, et.al.,1985). This research, "Will be a Guide for Running Spikes," says we may find spikes uncomfortable at first because of the lack of cushioning, and the sharp spikes located under the ball of our foot. There will be a period of adjustment until they become comfortable, and we may choose to use our regular running shoes for most of our training, and spikes for racing only. A big question arise on the minds of every athletes, coaches, trainers, physical therapists and physicians is whether running barefoot or running with spikes are better for athletes or not. In present study we try to find out answer of this question by experimental research. The results of the present study may be helpful for athletes, physical education teachers, coaches and sport trainers.

\section{Material and Methods}

For the purpose of the present study, Twenty-six ( $\mathrm{N}=26)$, Male Haryana Inter-Collegiate and State level runners between the age group of 17-25 years were selected as subject in this study. The subjects were purposively selected and tested two times for selected kinematic and kinetic variables in different conditions of running i.e., barefoot and running with spikes. The variables were selected according to the running activities i.e., $100 \mathrm{~m} \& 200 \mathrm{~m}$ sprint test to observe bare foot and running with spikes condition effects on athletes, acceleration ability (30 m sprint), stride frequency (by high knee action for one minutes), explosive leg strength (by standing broad jump) and force (by using formula $(\mathrm{f}=\mathrm{ma})$ ) The $400 \mathrm{~m}$ grassy standard track were used for sprint tests. The subjects were used their own routine training (5 or 7 nails) spikes. The subjects were belong to semi rural area and they were used to do running in bare foot, and running with shoe spikes. The data were analyzed by using ' $t$ ' test, to observe significant mean difference between bare foot and running with spikes condition of sprinters with the help of SPSS (version 11.5) computer software. 
Journal of Exercise Science \& Physiotherapy, Vol. 13, No. 1, 2017

ISSN: 0973-2020 (Print) I2OR Impact Factor $=5.23$ UGC Approved [no.20489]

(Online)

\section{Results and Discussion}

Table 1. Mean and SD of Kinematic and Kinetic variables of Sprinters running bare foot and with shoe spikes

\begin{tabular}{|c|c|c|c|c|c|}
\hline \multirow{2}{*}{ Variables } & \multicolumn{2}{|c|}{ Bare Foot } & \multicolumn{2}{|c|}{ Spikes } & \multirow{2}{*}{$\begin{array}{c}\text { T Test } \\
\text { 't' Ratio } \\
\end{array}$} \\
\hline & Mean & S.D. & Mean & S.D. & \\
\hline Age (year) & 16.92 & 1.302 & 16.92 & 1.302 & 0.00 \\
\hline Height(m) & 1.68 & 0.002 & 1.69 & 0.003 & 0.319 \\
\hline Weight (kg) & 57.55 & 49.06 & 57.99 & 49.54 & 0.223 \\
\hline 100 m sprint (Seconds) & 13.053 & 0.559 & 12.540 & 0.555 & $2.478^{*}$ \\
\hline 200 m sprint (Seconds) & 26.871 & 2.279 & 25.919 & 1.917 & $2.368 *$ \\
\hline $\begin{array}{l}30 \text { m sprint (Sec) } \\
\text { Acceleration Ability }\end{array}$ & 4.423 & 0.033 & 4.271 & 0.064 & $2.483^{*}$ \\
\hline Stride frequency & 25.923 & 9.514 & 24.308 & 13.982 & 1.699 \\
\hline Standing Broad Jump (m) & 2.517 & 0.016 & 2.607 & 0.022 & $2.353 *$ \\
\hline Force & 25.932 & 8.907 & 25.023 & 8.569 & 1.108 \\
\hline
\end{tabular}

Table 1 shows Mean and 't' ratio of kinematic and kinetic variables of sprinters running bare foot and shoe spikes. Results shows that the ' $\mathrm{t}$ ' ratio of $100 \mathrm{~m}$ sprint, $200 \mathrm{~m}$ sprint, acceleration ability and standing broad jump were differ significantly at .05 level of significance between bare foot and running with spikes conditions of sprinters.; Whereas no statistical significant difference was observed for stride frequency and force between both running conditions. Further the mean values of $100 \mathrm{~m}$ sprint, $200 \mathrm{~m}$ sprint, acceleration run ability of sprinters run with shoe spikes conditions were found less as compared to sprinters run with barefoot. The sprint time $(100 \mathrm{~m}, 200 \mathrm{~m}$, and $30 \mathrm{~m})$ is inversely related to performance of the sprinters, hence it clearly indicates that shoe spike sprinters perform better as compared to barefoot running sprinters. It was also found that mean value of explosive leg strength and stride frequency in spikes conditions was more than that of bare foot conditions of sprinters. As mean value indicates that in case of $100 \mathrm{~m}, 200 \mathrm{~m}$ and $30 \mathrm{~m}$ athletes performed better in condition of running with shoe spikes as compared to bare foot it is because runners running with flat/minimalist footwear have a wide stride length (longer flight phase); and lower strides frequency (slower turnover). In condition of running with spikes complete body leads by upper body; spikes enables the body's to absorb the shocks and forces, protects the foot from trauma and injuries and generate ground reaction force, whereas in case of explosive leg strength mean values also shows that athletes with spikes performed better than that of bare foot, it is due to while jumping Newton third law (action is equal and opposite to reaction) helps the sprinters to generate more ground reaction force with the help of spikes nails as compared to bare foot. Further, the bare foot runners performed better in stride frequency as compared to running with spikes condition it is due to in case of bare feet; runners leads on the outside middle of the foot and the initial force peak occurs very rapidly, while in spikes, there is negative drop from forefoot to heel in the quest to provide greater performance assistance to run fast; runners foot strike first then heel with ground and it increases the time taken for the initial force peak. Spikes also add mass to the foot, which slowing down the runners. Athletes running with bare foot also have a shorter stride length (Less flight phase); but higher stride frequency (faster turnover). In case of explosive leg 


\section{Journal of Exercise Science \& Physiotherapy, Vol. 13, No. 1, 2017 \\ ISSN: 0973-2020 (Print) $\quad I_{2}$ OR Impact Factor $=5.23$ UGC Approved [no.20489] \\ (Online)

strength sprinters performed better in spikes running condition as compared to bare feet it may be due to better grip with ground surface and ground reaction force and larger stride length. There is no authentic evidence that, as compared to running with shoe spikes the barefoot running has negative effects on performance of the sprinters. To be sure, most elite sprinters preferred to use spikes and minimal sole shoes because they protect the foot and allow one to run on rough and uneven surfaces without worrying about foot placement and protection/safety. Similar results were also reported by DeWit et al., (2000), Divert et al., (2005), Weyand et al., (2000), Cavanagh 1980 and Denton 2005.

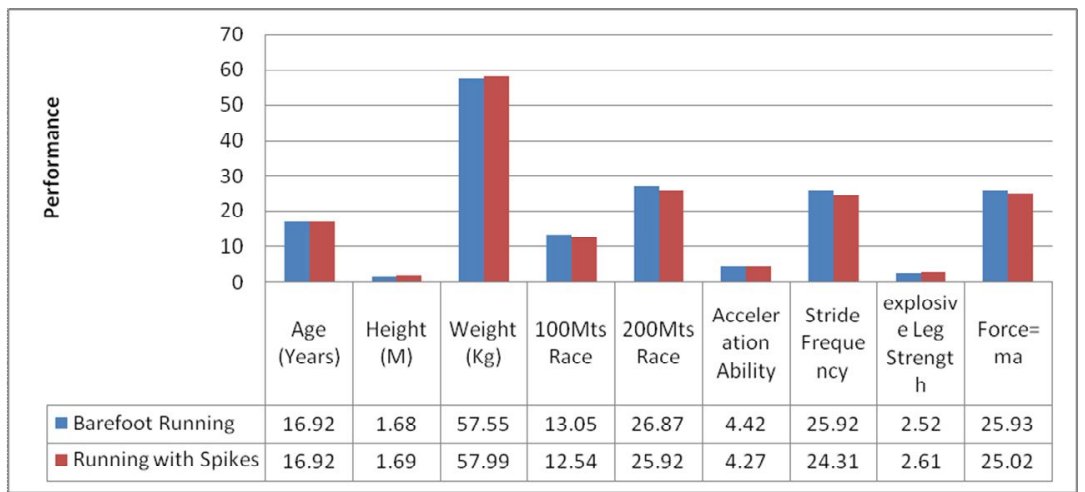

Figure.1 Barefoot Running vs Running with spikes

\section{Conclusion}

From the results of the present study it was concluded that shoe spike sprinters perform better for sprint of $100 \mathrm{~m}, 200 \mathrm{~m}, 30 \mathrm{~m}$, standing broad jump and force as compared to barefoot running sprinters. Whereas in case of stride frequency the bare foot runners was better than that with shoe spikes.

\section{References}

Barefoot runner.(2012).Visited 2012-05-23, at http://www.barefootrunner. Com/barefoot-101.

Cavanagh, P.R. (1980). In book:The Running Shoe. Mountain View, Anderson World.

Cavanagh, P.R. and Lafortune, M.A.(1980). Ground reaction forces in distance running. Journal of Biomechanics 13(5), 397-406.

Christensen, D.L.Nielsen, T.H., \& Schwartz, A. (2009). Herodotos and hemerodromi: Pheippides' run from Athens to Sparta in $490 \mathrm{BC}$ from historical and physiological perspectives. Hermes, 137(2), 148-148.

Christopher McDougall (2009). Born to Run: A Hidden Tribe, Superathletes, and the Greatest Race the World Has Never Seen, ethnography; Non-fiction American author and journalist.

Clement D.B., Taunton, J.E., Smart G.W. \& Mc Nicol, K.L. (1981) A survey of some overuse running injuries. Phys Sports Medicine Volume 1(3): Pp. 242-246.

Cook, S.D., Kester, M.A. and Brunet, M.E. (1985) Shock absorption characteristics of running shoes. American Journal of Sports Medicine 13(4), 248-253.

Denton, J.D. (2005). Light does not make right. Running Times 324, 78.

DeWit, B., De Clercq, D. and Aerts, P. (2000). Biomechanical analysis of the stance phase during barefoot and shoe running. Journal of Biomechanics 33(3), 269-278.

Divert, C., Mornieux, G., Baur, H., Mayer, F. and Belli, A. (2005). Mechanical comparison of barefoot and shoe running. International Journal of Sports Medicine 26(7), 593-598. 
(Online)

Lafortune, Mario (2008) The Role of Research in the Development of Athletic Footwear. Journal of Foot and Ankle Research Volume 1 Supplement 1 Pp. 110.

Lieberman, Daniel E. (2012). What We Can Learn About Running from Barefoot Running: An Evolutionary Medical Perspective. Department of Human Evolutionary Biology, Harvard University, Cambridge MA; American College of Sports Medicine. 40(2), Pp 70.

Nigg, B.M. and Wakeling, J.M. (2001). Impact forces and muscle tuning: a new paradigm. Exercise and Sports Science Review 29, 37-41.

Weyand, P.G., Sternlight, D.B., Bellizzi, M.J. and Wright, S. (2000). Faster top running speeds are achieved with greater ground forces not more rapid leg movements. Journal of Applied Physiology 89(5), 1991-1999.

William A. Rossi, D.P.M. (2001). Footwear: The Primary Cause of Foot Disorders. Podiatry Management. Part- II pp. 129-138.

Conflict of Interest: None declared 